\title{
Central Administration of a Cytochrome P450-7B Product $7 \alpha$-Hydroxypregnenolone Improves Spatial Memory Retention in Cognitively Impaired Aged Rats
}

\author{
Joyce L. W. Yau, June Noble, Mags Graham, and Jonathan R. Seckl \\ Endocrinology Unit, The Queen's Medical Research Institute, University of Edinburgh, Edinburgh EH16 4TJ, United Kingdom
}

\begin{abstract}
Pregnenolone (PREG) and dehydroepiandrosterone (DHEA) have been reported to improve memory in aged rodents. In brain, these neurosteroids are transformed predominantly into $7 \alpha$-hydroxylated metabolites by the cytochrome P450-7B1 (CYP7B). The biological role of steroid B-ring hydroxylation is unclear. It has been proposed to generate bioactive derivatives that enhance cognition, immune, and other physiological processes. In support, $7 \alpha$-hydroxylated DHEA increases the immune response in mice with greater potency than the parent steroid. Whether the memory-enhancing effects of PREG in rats is mediated via its $7 \alpha$-hydroxylated metabolite $7 \alpha$ hydroxyPREG is not known. We investigated this by treating memory-impaired aged rats (identified by their spatial memory performances in the Morris water maze task compared with young controls) with $7 \alpha$-hydroxyPREG or PREG administered intracerebroventricularly using osmotic minipumps and then tested the rats during week 2 of steroid treatment in the eight-arm radial-arm version of the water maze (RAWM) that allows repeated assessment of learning. CYP7B bioactivity in hippocampal tissue (percentage conversion of $\left[{ }^{14} \mathrm{C}\right]$ DHEA to $\left[{ }^{14} \mathrm{C}\right] 7 \alpha$-hydroxyDHEA) was decreased selectively in memory-impaired aged rats compared with both young and memory-intact aged rats. $7 \alpha$-hydroxyPREG $(100 \mathrm{ng} / \mathrm{h})$ but not PREG $(100 \mathrm{ng} / \mathrm{h})$ administration to memory-impaired aged rats for $11 \mathrm{~d}$ enhanced spatial memory retention (after a 30 min delay between an exposure trial 1 and test trial 2) in the RAWM. These data provide evidence for a biologically active enzyme product $7 \alpha$-hydroxyPREG and suggests that reduced CYP7B function in the hippocampus of memory-impaired aged rats may, in part, be overcome by administration of $7 \alpha$-hydroxyPREG.
\end{abstract}

Key words: neurosteroids; hippocampus; water maze; DHEA; pregnenolone; aging

\section{Introduction}

In addition to being a prime target site of peripheral steroid hormones, the brain itself can also synthesize steroids de novo from cholesterol or by in situ metabolism of blood-borne precursors (Robel and Baulieu, 1995; Vallee et al., 2004). Blood levels of dehydroepiandrosterone (DHEA) in humans decline significantly with age and parallels cognitive decline (Orentreich et al., 1992). Rodents, in contrast, have very little DHEA in brain because of the lack (or undetectable levels) of cyp17 $\alpha$ (17 $\alpha$ hydroxylase) that catalyzes the conversion of pregnenolone (PREG) to DHEA in rat and mouse adrenal cortex (Le Goascogne et al., 1991; Mellon and Deschepper, 1993). However, high levels of PREG, the neurosteroid precursor of DHEA, can be detected in the hippocampus of young rats, whereas aged rats have lower levels, which correlate with cognitive deficits (Vallee et al., 1997). PREG administration improves learning and memory in rats and

Received Dec. 8, 2005; revised Sept. 16, 2006; accepted Sept. 18, 2006.

This work was supported by a Biotechnology and Biological Sciences Research Council Science into Ageing grant (J.L.W.Y., J.R.S.) and an Alzheimer's Research Trust Carter Fellowship (J.L.W.Y.). We thank Drs. D. M. Diamond and W. B. Rowe for their helpful discussions on the radial arm water maze protocol.

Correspondence should be addressed to Dr. Joyce L. W. Yau, Endocrinology Unit, The Queen's Medical Research Institute, University of Edinburgh, 47 Little France Crescent, Edinburgh EH16 4TJ, UK. E-mail: joyce.yau@ed.ac.uk. DOI:10.1523/JNEUROSCI.3189-06.2006

Copyright $\odot 2006$ Society for Neuroscience $\quad$ 0270-6474/06/2611034-07\$15.00/0 mice (Flood et al., 1992, 1995; Vallee et al., 1997), but the mechanisms involved are unclear.

Local metabolism may influence steroid activity by converting precursor steroid to active or inactive metabolites (Mellon and Deschepper, 1993; Seckl, 1997). We have previously characterized a novel cytochrome P450-7B1 (CYP7B), from a rat hippocampal cDNA library (Stapleton et al., 1995). CYP7B, unusually for a cytochrome P450, is highly expressed in brain, particularly in the hippocampus (Rose et al., 1997). DHEA and PREG are converted to their respective $7 \alpha$-hydroxylated metabolites by recombinant CYP7B in vitro (Rose et al., 1997). The main product of DHEA or PREG incubation with rat brain extracts is also $7 \alpha$-hydroxyDHEA or $7 \alpha$-hydroxyPREG (Akwa et al., 1992), suggesting that the major metabolic route for these neurosteroids in brain is $7 \alpha$-hydroxylation by CYP7B metabolism. Extrahepatic tissues from homozygous $C y p 7 b^{-1-}$ mice (including brain) fail to metabolize DHEA and PREG to their major $7 \alpha$ (and 7 $\beta$ ) products (Rose et al., 2001). Thus, outside the liver, CYP7B provides the primary metabolic route for DHEA, PREG, and related $3 \beta$-hydroxysteroids. The role played by the $7 \alpha$ hydroxy metabolites in brain is not clear. Intriguingly, CYP7B may convert precursor steroids to active products. Thus, $7 \alpha-$ hydroxyDHEA, but not DHEA, is neuroprotective in hippocampal cultures, reducing ischemia-induced neuronal damage in vitro (Pringle et al., 2003). Similarly, $7 \alpha$-hydroxyDHEA, but not 
DHEA, acts as an immune stimulant in vitro (Lafaye et al., 1999). Given that PREG (and DHEA) have been proposed to be protective against age-associated cognitive decline (Flood and Roberts, 1988; Vallee et al., 2001), a clear understanding of whether local metabolism by CYP7B in the hippocampus regulates its effects on cognition merits investigation. To test this, we exploited the considerable interindividual differences in cognitive abilities found in aged rats (Issa et al., 1990; Gallagher et al., 1993; Yau et al., 1995; Vallee et al., 1997) to first determine whether hippocampal CYP7B bioactivity is related to spatial memory impairments with aging in rats and second whether central administration of the PREG metabolite of CYP7B metabolism, $7 \alpha$-hydroxyPREG, can improve spatial memory in cognitively impaired aged rats.

\section{Materials and Methods}

Animals. Male Lister Hooded rats (Charles River, Kent, UK) were obtained at 3 months of age and maintained for up to 26 months under conditions of controlled lighting (lights on from 7:00 A.M. to 7:00 P.M.) and temperature $\left(22^{\circ} \mathrm{C}\right.$ ), with ad libitum access to food (CRM diet cubed; Special Diet Services, Essex, UK) and tap water. The health status was monitored weekly by a veterinarian; animals showing overt signs of respiratory distress, infection, or tumors were excluded. All procedures were performed in strict accordance with the United Kingdom Animals (Scientific Procedures) Act (1986).

Morris water maze. Young ( 6 months old; $n=12)$ and aged rats $(24$ months; $n=48)$ (500-600 g body weight) were tested for their spatial learning performance in the Morris water maze, as described previously (Yau et al., 1995). The maze consisted of a 1.8-m-diameter circular white fiberglass pool filled to a depth of $35 \mathrm{~cm}$ with water $\left(25^{\circ} \mathrm{C}\right)$ made opaque with the addition of nontoxic white latex paint and was in a room with extramaze cues on the walls around the pool. A circular escape platform (10 $\mathrm{cm}$ diameter) was submerged $1.5 \mathrm{~cm}$ below the water surface in one of the quadrants of the pool, and this position remained constant throughout testing. All rats were first habituated to the maze with a $60 \mathrm{~s}$ free swim in the pool and were then given 16 trials over 4 consecutive days to learn the location of the submerged platform (four trials per day; $120 \mathrm{~s}$ maximum trial duration; $30 \mathrm{~s}$ intertrial interval). Latencies to locate the hidden platform and swim paths were monitored by a video camera mounted in the ceiling and a computerized tracking system [HVS image analyzer (Kingston, UK) and Acorn Archimedes computer]. On day 5, the rats were given a $60 \mathrm{~s}$ retention test of the spatial location (probe test) with the platform absent, and the percentage time in the pool quadrants was recorded. Finally, the rats were given four $60 \mathrm{~s}$ trials (visually cued) in which the platform was raised $1 \mathrm{~cm}$ above the water level and had a cardboard flag $(8 \times 5 \mathrm{~cm})$ placed securely on top to render it visible. This tested for visual, motivational, or motor deficits that may have influenced performance.

The cognitive status of the aged rats was defined on the basis of their latencies to find the platform on days 3 and 4 of testing relative to the mean latency of the young rats. Aged impaired (AI) rats were defined as those animals with mean latencies that differed by $>2$ SDs from that of the young controls. Aged unimpaired (AU) rats were identified as those whose performance (mean latencies over days 3 and 4 ) was $\leq 0.5 \mathrm{SD}$ from that of young controls. Aged rats that were intermediate were not further used in the present study. The $7 \alpha$-hydroxylase activity in the hippocampus from a selection of the cognitively tested rats was determined. Rats were killed in the morning by decapitation, and brains were dissected and stored frozen at $-80^{\circ} \mathrm{C}$ before the assay. To generate sufficient numbers of age-impaired rats to study the effects of central administration of pregnenolone and $7 \alpha$-hydroxypregnenolone on spatial memory, another cohort of aged rats $(n=27)$ and young controls $(n=6)$ were screened for their spatial learning performance in the Morris water maze as above. The brains from the cognitively tested rats not used in the enzyme bioactivity assays or steroid treatment studies were stored at $-80^{\circ} \mathrm{C}$ for future simultaneous quantification of endogenous levels of PREG, DHEA, and their $7 \alpha$-hydroxylated metabolites.

CYP7B bioactivity. Individual hippocampi from young $(n=6)$ and aged rats defined as cognitively impaired and unimpaired $(n=6$ per group) from the water maze testing were homogenized in $3 \mathrm{vol}$ of icecold PBS (containing $1 \mathrm{~mm}$ EDTA, 20\% glycerol, and protease inhibitors) and centrifuged at $4000 \times g$ for $5 \mathrm{~min}$ at $4^{\circ} \mathrm{C}$. The supernatant was removed, and protein concentration was determined, aliquoted, and stored at $-80^{\circ} \mathrm{C}$ until use. Ethanol solutions of $\left[{ }^{14} \mathrm{C}\right]$ DHEA $(53.8 \mathrm{mCi} /$ $\mathrm{mmol}, 0.02 \mathrm{mCi} / \mathrm{ml})$ were made (1:10 dilution) and dried down in glass tubes. Incubations were performed in a total volume of $200 \mu \mathrm{l}$ constituting of W buffer (0.1 м KPO4 and 1 mM EDTA, pH 7.4) and hippocampal extract ( $0.5 \mathrm{mg}$ protein). The tubes were vortexed and placed in a shaking water bath at $37^{\circ} \mathrm{C}$, and $25 \mu \mathrm{l}$ of $8 \mathrm{~mm} \mathrm{NADPH}$ was added (to give final concentration of $1 \mathrm{~mm}$ ). After incubating for $30 \mathrm{~min}$, the reactions were stopped by placing the tubes on ice and extracting the steroids $(2 \times 500 \mu \mathrm{l}$ ethyl acetate). The organic phase was dried down under compressed air at $60^{\circ} \mathrm{C}$ and was resuspended in $30 \mu \mathrm{l}$ of ethyl acetate. The reaction constituents were applied to silica thin-layer chromatography (TLC) plates (Merck Biosciences, Nottingham, UK) and developed in solvent solution (ethyl acetate, $n$-hexane, and acetic acid, 16:8:1). Reaction substrates and products were visualized and quantified by a phosphoimager.

Treatment and behavioral testing schedule. The performance of old rats in spatial learning tasks can be significantly influenced by previous exposure to that task, even months earlier (van Groen et al., 2002). To avoid this, the animals were retested during intracerebroventricular neurosteroid treatment in a spatial working memory task using the radial arm water maze (RAWM) because it has been reported that age-related memory impairments are lost with repeated testing in the water maze, whereas previous experience in the water maze did not have any effect on learning of the radial maze (Dellu et al., 1997). This is a cognitively more demanding spatial learning task, so the age-impaired rats assigned for treatment and young controls were first trained in the RAWM for $5 \mathrm{~d}$ (with no delays between trials; see below) before the start of neurosteroid treatment. One week after stereotaxic implantation of brain cannulas and osmotic minipumps, the rats were tested in the RAWM (during week 2 of osmotic minipump drug delivery) and were given five trials per day with no delays for $3 \mathrm{~d}$. Then on the next 2 consecutive days, they were each given a 30 min delay retention test between trials 1 and 2 . At the end of the osmotic minipump action $2 \mathrm{~d}$ later, all rats were killed in the morning (9:00 -10:00 A.M.) by decapitation, trunk blood was collected in EDTAcoated tubes for corticosterone measurements, and brains were removed and stored frozen $\left(-80^{\circ} \mathrm{C}\right)$.

Surgery and steroid treatment. Animals were anesthetized with halothane and subjected to stereotaxic implantation of chronic indwelling stainless steel cannulas (Alzet brain infusion cannula; Alza, Palo Alto, $\mathrm{CA}$ ) into the lateral ventricle (coordinates were as follows: anteroposterior, $1.0 \mathrm{~mm}$ posterior to bregma; lateral, $1.5 \mathrm{~mm}$; dorsoventral, $4.5 \mathrm{~mm}$ ventral to dura). The cannula was secured to the skull with dental acrylic, and the external part of the intracerebroventricular cannula was connected with polyethylene tubing to an Alzet osmotic minipump (2 weeks, $0.5 \mu \mathrm{l} / \mathrm{h}$; model 2002; Alza) placed subcutaneously behind the neck. Steroids were dissolved in artificial CSF with $10 \%$ hydroxypropyl betacyclodextrine (a polymer that is nontoxic and devoid of intrinsic effects, used to dissolve hydrophobic compounds in aqueous media). A selection of the aged rat cohort with significantly impaired spatial learning compared with young controls (as assessed in the Morris water maze task) were randomly allocated to treatment with PREG (100 ng/h, $n=6$; Sigma, Poole, UK), $7 \alpha$-hydroxyPREG (100 ng/h, $n=7$; Steraloids, Newport, $\mathrm{RI})$, or vehicle $(0.5 \mu \mathrm{l} / \mathrm{h}, n=8)$. A young control vehicle group $(0.5$ $\mu \mathrm{l} / \mathrm{h}, n=6$ ) was also included. All rats were singly housed after surgery. The dose of PREG chosen was based on a previous study that showed significantly increased memory performance with 100 ng/h PREGsulfate (S) given intracerebroventricularly in mice (Ladurelle et al., 2000) and acute doses used in other studies (Flood and Roberts, 1988; Flood et al., 1992). The estimated rate of CSF production in the nervous system of mice is $\sim 20 \mu \mathrm{l} / \mathrm{h}$, whereas in rats it was $\sim 520 \mu \mathrm{l} / \mathrm{h}$ (Ladurelle et al., 2000), so the highest effective dose was chosen because this will be effectively diluted by the greater volume of CSF in the rat. No other study has tested the effects of the $7 \alpha$-hydroxylated metabolites on memory performance and the endogenous levels in brain are not known, so the same dose as the parent steroid was used for comparison. 
Radial arm water maze. The RAWM consisted of the $1.8 \mathrm{~m}$ circular pool with eight white polypropylene inserts ( $54 \mathrm{~cm}$ high) within the tank that divide the pool into eight swim paths (59-cm-long arms) radiating out of an open central area ( $62 \mathrm{~cm}$ diameter). This spatially more complex task forces the rat to swim in either the central open area or one of the arms and takes advantage of the variable spatial complexity of the radial arm maze and the efficient learning of the water maze (Diamond et al., 1999). A hidden platform (10 cm diameter) was located in one of the arms $1.5 \mathrm{~cm}$ below the water surface at least $8 \mathrm{~cm}$ from the tank wall and remained in the same position within $1 \mathrm{~d}$ but was in a different arm across days. Each trial began with the rat placed directly in the entrance of one of the arms with no hidden platform ("start arm") with the rat facing the central area. Start locations were randomized. Young and aged rats were given five trials per day ( $60 \mathrm{~s}$ maximum duration) to locate the platform. If the rat did not find the platform in $60 \mathrm{~s}$, it was guided to the platform by the experimenter. The rat remained on the platform for $30 \mathrm{~s}$ before the next trial was initiated. The latency to find the platform was recorded, and the number of errors made per trial was noted. An error was committed when a rat entered an arm that did not contain the platform or if a rat entered the correct arm but did not find the platform. For the memory retention trial, a 30 min delay period was used after the first trial. During this time, the rat was dried in a towel and placed in its cage under a warming lamp. The rest of the trials continued with no delay. The 30 min delay was chosen because a longer delay of 60 min impaired memory retention in young rats in our pilot studies (data not shown).

Corticosterone levels. Plasma corticosterone levels were measured by radioimmunoassay modified for microtiter plate scintillation proximity assay (Amersham Biosciences, Little Chalfont, UK) with a highly specific antiserum (Dr. C. Kenyon, University of Edinburgh, Edinburgh, UK) and $\left[{ }^{3} \mathrm{H}\right]$ corticosterone (Amersham Biosciences).

Statistical analysis. Data were analyzed using one- or two-way ANOVA with the age and treatment as between-subject factors. Scheffe's tests were applied for post hoc analysis. For spatial learning in the Morris water maze, the repeated within-subject factor was the day, and, for spatial working memory in the RAWM, the trial was the within-subject factor. All data are expressed as group means \pm SEM. Significance was defined as $p<0.05$ or $p<0.01$.

\section{Results}

Water maze spatial learning impairments only in a subgroup of aged rats

Across the $4 \mathrm{~d}$ of training, escape latencies decreased $\left(F_{(3,189)}=\right.$ 59.9; $p<0.001)$ in both young and aged rats as they showed learning of the submerged platform location. The aged rat cohort exhibited significantly higher mean escape latencies than the young controls $\left(F_{(1,63)}=16.5 ; p<0.05\right)$ on each day (Fig. $\left.1 A\right)$. Of the 48 aged rats tested, 25\% were classed as cognitively AI and $25 \%$ AU (Fig. $1 B$ ). The first trial latencies on day 1 of spatial training were not significantly different between young and aged rats $(p=0.19$; young, $70.3 \pm 11.5 \mathrm{~s}$; AI, $96.7 \pm 10.3 \mathrm{~s}$; AU, $92.3 \pm$ $10.7 \mathrm{~s}$ ). In contrast, the mean escape latencies (block of four trials) were significantly different between AI and AU rats $(p<$ 0.001 ) but not between AU and young controls for each of days 2-4 (Fig. $1 B$ ). The day after the last acquisition trial, each rat was given a $60 \mathrm{~s}$ probe test with the submerged platform absent from the pool. AI animals spent significantly less time in the target quadrant of the pool compared with either AU or young rats $\left(F_{(2,38)}=8.3 ; p<0.01\right)$, whereas AU did not significantly differ from young controls (Fig. $1 C$ ). Swim speeds were similar in young and aged rats $(p=0.07$; young, $20.7 \pm 0.6 \mathrm{~cm} / \mathrm{s}$; AU, $18.3 \pm 0.5 \mathrm{~cm} / \mathrm{s} ;$ AI, $19.8 \pm 0.9 \mathrm{~cm} / \mathrm{s})$, suggesting no motor deficit to explain differences in latency in AI rats. Furthermore, there was no significant difference in latencies to locate the visible platform between $\mathrm{AI}(6.8 \pm 0.8 \mathrm{~s})$ and $\mathrm{AU}(5.7 \pm 0.3 \mathrm{~s})$ or young $(6.3 \pm 0.5 \mathrm{~s})$, indicating that the impaired spatial memory per-
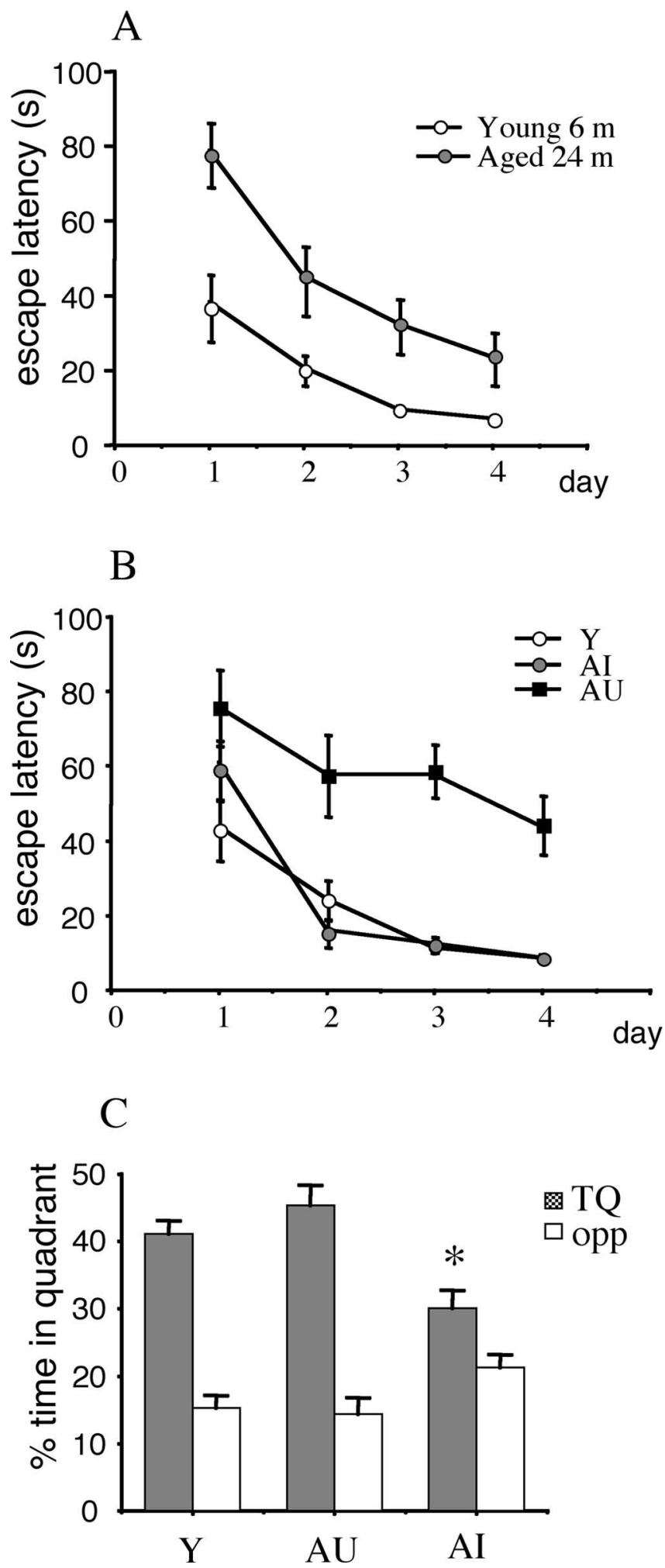

Figure 1. Aged rats can be classed into distinct subgroups according to their spatial learning performance in the Morris water maze. $A$, Aged ( $24-26$ months; $n=48$ ) rats showed overall impaired spatial learning (mean escape latency across days of training) compared with young 6-month-old controls $(n=17) \cdot \boldsymbol{B}, \mathrm{Al}(n=12)$ and $\mathrm{AU}(n=12)$ rats were defined according to their mean latencies across days 3 and 4 relative to the mean latency of the young $(Y)$ rats (see Materials and Methods); those in between are not shown. C, During the probe test ( $60 \mathrm{~s}$ free swim in the absence of platform in the pool), Al rats showed impaired spatial memory retention, spending significantly less time searching in the platform quadrant (TQ) but not in the opposite quadrant (opp) compared with young or AU rats. Data are mean values \pm SEM. ${ }^{*} p<0.01$ compared with both unimpaired and young. 


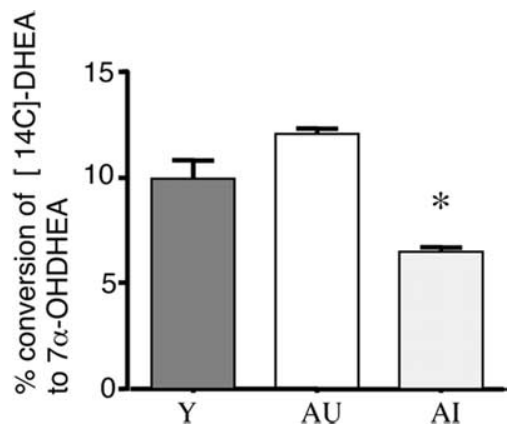

Figure 2. Decreased CYP7B bioactivity in hippocampal tissue from cognitively impaired aged rats. Hippocampal CYP7B bioactivity (as measured by the percentage conversion of $\left[{ }^{14} \mathrm{C}\right]$ DHEA to $\left[{ }^{14} \mathrm{C}\right] 7 \alpha$-hydroxyDHEA during a $30 \mathrm{~min}$ incubation) is decreased selectively in cognitively impaired aged 24-month-old rats (Al, $n=6$ ) compared with age-matched cognitively intact rats (AU, $n=4$ ) and young 6-month-controls $(n=6) .{ }^{*} p<0.05$ compared with $\mathrm{AU}$ and young.

formance of the AI animals is not a consequence of poor vision or inability to swim during this task.

CYP7B bioactivity is selectively decreased in the hippocampus of cognitively impaired aged rats

The $7 \alpha$-hydroxylase activity of CYP7B in the hippocampus was measured by incubating hippocampal microsomes from young, $\mathrm{AI}$, and $\mathrm{AU}$ rats with $\left[{ }^{14} \mathrm{C}\right] \mathrm{DHEA}$ as substrate and then identification of the $\left[{ }^{14} \mathrm{C}\right] 7 \alpha$-hydroxyDHEA metabolite produced based on the retention factor identical to that of the reference steroid on TLC plates. DHEA was chosen rather than PREG because this has been found previously to be the preferred substrate in rat brain microsomes (Akwa et al., 1992; Rose et al., 1997). CYP7B bioactivity was decreased $\left(F_{(2,12)}=13 ; p<0.01\right)$ selectively in AI compared with young (34\% reduction) and $\mathrm{AU}$ ( $45 \%$ reduction) rats, whereas AU rats showed similar CYP7B bioactivity to young controls (Fig. 2).

\section{Spatial memory and RAWM performance of rats before intracerebroventricular administration of PREG or $7 \boldsymbol{\alpha}$-hydroxyPREG}

The individual aged rat treatment groups did not differ in their spatial learning (escape latency across days; repeated-measures ANOVA, $F_{(2,18)}=0.08 ; p=0.92$ ) (Fig. $3 A$ ) before neurosteroid administration. All three aged rat treatment groups showed impaired spatial learning compared with young controls $(p<0.05)$ (Fig. 3A). Spatial working memory, tested in the RAWM, did not differ between aged rat treatment groups $\left(F_{(2,18)}=0.46 ; p=\right.$ $0.64)$. All three aged rat treatment groups show significantly impaired spatial working memory (within-days mean trials over 3 consecutive days) compared with young controls $(p<0.01)$ (Fig. 3B).

\section{RAWM working memory of aged rats after intracerebroventricular administration of PREG or $7 \boldsymbol{\alpha}$-hydroxyPREG}

Vehicle-control aged rats showed impaired short-term working memory (within-days mean trials over days 8 and 9 of treatment) compared with young vehicle controls (repeated-measures ANOVA, $\left.F_{(1,12)}=7.2 ; p<0.05\right)$ (Fig. $\left.4 A\right)$. Neither PREG $\left(F_{(1,12)}=\right.$ $0.48 ; p=0.5)$ nor $7 \alpha$-hydroxyPREG $\left(F_{(1,13)}=0.33 ; p=0.57\right)$ significantly affected short-term spatial learning in the aged rats (Fig. 4A). Trial 1 latencies $\left(F_{(3,23)}=0.85 ; p=0.48\right)$ and errors $\left(F_{(3,23)}=1.1 ; p=0.38\right)$ did not differ between the treatment
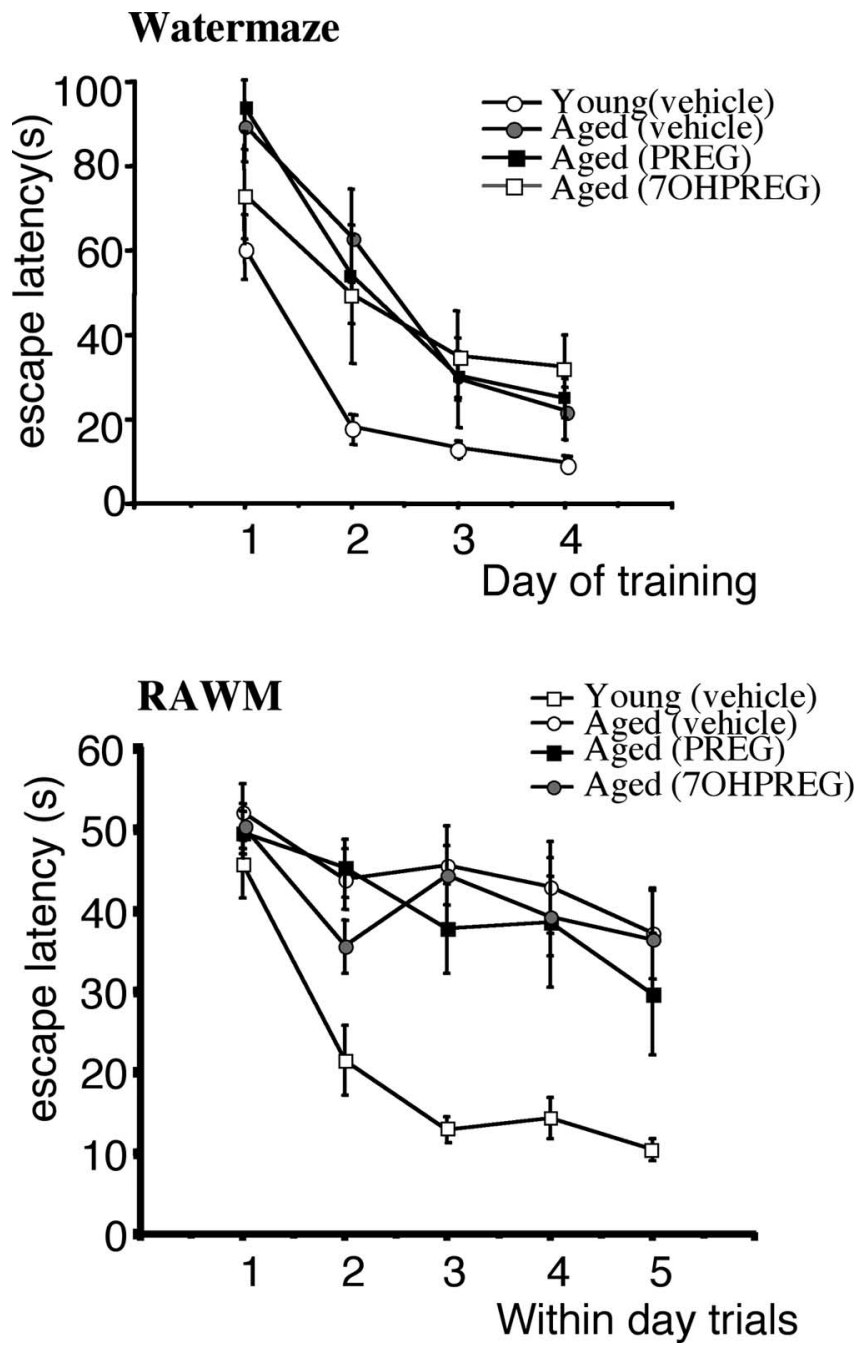

Figure 3. Cognitive status of aged rats before steroid treatment. Before treatment, aged 24-month-old rats assigned to the different treatment groups ( $n=6-8 /$ group) were equally impaired in learning the across-days location (Morris water maze) and within-day location (RAWM) of the platform compared with young 6-month-old controls $(n=6)$. Data shown for each within-day trials in RAWM are mean \pm SEM values over 3 consecutive days.

groups. On days 10 and 11 of treatment, young vehicle controls show retention of the platform location after a 30 min delay, as indicated by a decrease in trial 2 latency compared with trial 1 $(p<0.001$, paired $t$ test) (Fig. $4 B$ ). In contrast, aged vehicle rats showed impaired spatial memory retention (trials 1 and 2 latencies did not differ; $p=0.64$, paired $t$ test) (Fig. $4 B$ ). Aged vehicle controls were impaired in both escape latencies $\left(F_{(1,12)}=16.5\right.$; $p<0.01)$ and errors $\left(F_{(1,12)}=28.4 ; p<0.001\right)$ compared with young vehicle controls. $7 \alpha$-hydroxyPREG improved spatial memory retention in the AI rats compared with aged vehicle controls in both escape latencies $\left(F_{(1,13)}=7.6 ; p<0.05\right)$ and errors $\left(F_{(1,13)}=8.2 ; p<0.05\right)$, and this was not significantly different from young vehicle controls (Fig. $4 B$ ). In contrast, PREG had no significant effect on spatial memory retention in AI rats compared with aged vehicle controls in both escape latencies $\left(F_{(1,12)}=2.6 ; p=0.13\right)$ and errors $\left(F_{(1,12)}=4.1 ; p=0.07\right)$ (Fig. $4 B)$.

\section{Swim speeds and plasma corticosterone levels}

The average swim speeds was not influenced by treatment $\left(F_{(3,23)}=\right.$ $1.6 ; p=0.2)$, but all groups did show significantly increased swim 
speeds across the five trials $\left(F_{(4,92)}=22.9\right.$; $p<0.001$ ) (Table 1). Plasma corticosterone levels measured from trunk blood was not significantly affected by treatment (young, $9.59 \pm 1.9 \mu \mathrm{g} / \mathrm{dl}$; old, vehicle, $13.3 \pm 1.8 \mu \mathrm{g} / \mathrm{dl}$; old, PREG, $13.4 \pm 5.6$ $\mu \mathrm{g} / \mathrm{dl}$; old, $7 \alpha$-hydroxyPREG, $7.6 \pm 1.6$ $\mu \mathrm{g} / \mathrm{dl})$.

\section{Discussion}

Although tissue-specific metabolism of glucocorticoids by $11 \beta$-hydroxysteroid dehydrogenase type 1 (11 $\beta$-HSD1) affects hippocampal-dependent learning and memory in aged mice (Yau et al., 2001), little is known about any analogous importance of local metabolism of neurosteroids such as DHEA and PREG. The major ex vivo metabolic route for PREG and DHEA in brain is $7 \alpha$-hydroxylation by CYP7B (Stapleton et al., 1995), a reaction that is conserved across mammalian species, including primates and humans (Akwa et al., 1992; Doostzadeh and Morfin, 1996; Weill-Engerer et al., 2003; Yau et al., 2003). Here we describe, for the first time, (1) a significant and selective decrease in hippocampal CYP7B bioactivity in aged 24-month-old rats with impaired spatial memory performance in the water maze but not in age-matched cognitively intact rats and (2) treatment with the CYP7B product $7 \alpha$-hydroxyPREG to $\operatorname{cog}$ nitively impaired aged rats enhances spatial memory retention after a 30 min delay in the radial arm water maze, whereas PREG, the parent steroid, had no significant effect at the dose tested.

We found large interindividual differences in the spatial memory performances of aged rats in the Morris water maze, consistent with previous reports (Issa et al., 1990; Gallagher et al., 1993; Yau et al., 1995). Hippocampal CYP7B bioactivity was reduced selectively in aged-impaired, but not in aged unimpaired, rats that maintained levels similar to young controls. Decreased hippocampal CYP7B bioactivity is therefore not an inevitable consequence of aging. A previous study also reported somewhat lower $7 \alpha$-hydroxylation of PREG and DHEA by mouse brain microsomes with age (Doostzadeh and Morfin, 1996), albeit the oldest mice tested were only 10 months old, less than half their lifespan, and these were compared with 2-monthold juveniles [CYP7B expression in hippocampus shows a complex ontogeny (Bean et al., 2001)]. Hippocampal PREG levels decline with age and correlate with cognitive impairments in rats (Vallee et al., 1997), suggesting that both the substrate for CYP7B and the enzyme itself may decline in a subset of aged rodents with cognitive deficits. Interestingly, CYP7B mRNA levels are markedly reduced in surviving hippocampal neurons of Alzheimer's disease postmortem brain compared with age-matched controls without CNS disease (Yau et al., 2003). It is unknown whether CYP7B bioactivity decreases in parallel with its mRNA expression or whether this occurs in cognitive impairment without frank trials $3-5$.
B
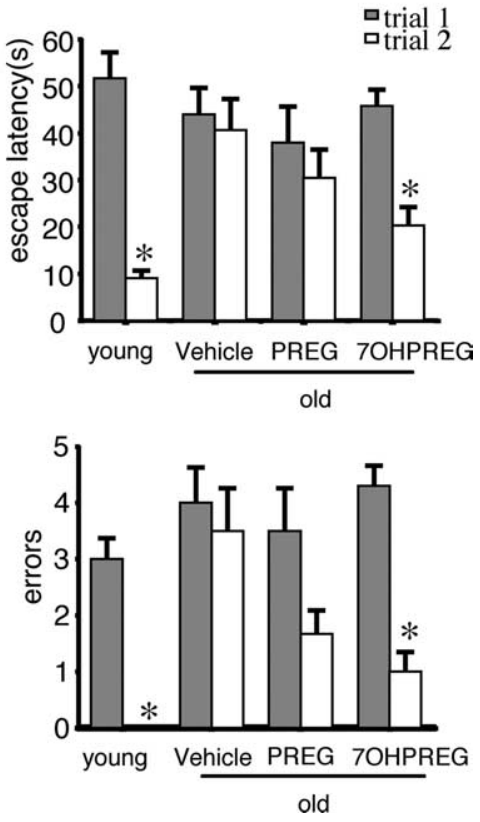

Figure 4. A, PREG and $7 \alpha$-hydroxyPREG treatment had no effect on short-term spatial learning in aged rats. After treatment, aged vehicle controls were impaired in short-term learning compared with young vehicle controls in the eight-arm radial water (with hidden platform in different arm each day). PREG and $7 \alpha$-hydroxyPREG did not affect short-term learning (acquisition (days 8 and 30 s intertrial interval) in the aged rats. Data shown for each trial are mean \pm SEM values over 2 consecutive days (days 8 and 9 of treatment). $B, 7 \alpha$-HydroxyPREG improves spatial memory retention in aged rats. Aged vehicle controls show (0.0 eight-arm radial water maze [increased escape latency $(p<0.05)$ and errors $(p<$ consecutive days (days 10 and 11 of treatment). ${ }^{*} p<0.001$ compared with corresponding trial 1.

Table 1. Average swim speeds $(\mathrm{cm} / \mathrm{s})$ of young and aged rats in the radial arm water maze after intracerebroventricular pregnenolone and $7 \alpha$-hydroxypregnenolone administration

\begin{tabular}{llllll}
\hline Treatment & Trial 1 & Trial 2 & Trial 3 & Trial 4 & Trial 5 \\
\hline Young (vehicle) & $17 \pm 0.9$ & $16 \pm 0.5$ & $22 \pm 2.1$ & $23 \pm 1.2$ & $23 \pm 0.9$ \\
Old (vehicle) & $17 \pm 1.3$ & $16 \pm 1.1$ & $18 \pm 1.5$ & $21 \pm 1.1$ & $20 \pm 1.1$ \\
Old (PREG) & $15 \pm 0.9$ & $15 \pm 1.5$ & $16 \pm 1.2$ & $20 \pm 2.2$ & $19 \pm 1.6$ \\
Old (7 $\alpha$-hydroxyPREG) & $17 \pm 0.6$ & $17 \pm 1.0$ & $19 \pm 1.3$ & $22 \pm 2.2$ & $21 \pm 1.3$ \\
\hline
\end{tabular}

Data are mean \pm SEM of the average swim speeds after $11 \mathrm{~d}$ of steroid treatment in the RAWM with a 30 min delay between trials 1 and 2 and no delays for

dementia in aging humans. Nonetheless, data from rodents and humans are consistent with an association between reduced hippocampal CYP7B function and cognitive decline with aging.

Although recent studies have reported anti-glucocorticoid, immunomodulatory, and antiapoptotic effects of $7 \alpha$ hydroxylated DHEA (Loria and Padgett, 1998; Hampl et al., 2000; Morfin and Starka, 2001; Pringle et al., 2003) and $7 \alpha$ hyroxyPREG (Morfin and Courchay, 1994), the effect of the CYP7B metabolites on memory have not been examined. Although CYP7B bioactivity was assayed with $\left[{ }^{14} \mathrm{C}\right] \mathrm{DHEA}$ as the preferred substrate based on previous findings (Akwa et al., 1992; Rose et al., 1997), we chose to examine the effects of PREG and its $7 \alpha$-hydroxylated metabolite on memory in the aged-impaired rats because this is the more abundant neurosteroid in rodent brain. DHEA is mostly a human steroid with very low levels detected in rodent brain; one recent study detected $0.27 \mathrm{ng} / \mathrm{g}$ DHEA in adult rat brain (Ebner et al., 2006). PREG, at least at the dose tested, which has been shown previously to enhance memory retention in young rodents (Ladurelle et al., 2000) and transiently 
improve memory deficits in cognitively impaired aged rats (Vallee et al., 1997), did not significantly improve spatial memory retention in aged impaired rats (after a 30 min delay in RAWM), although there was a trend for improved memory (decreased errors and latency after delay). It may be that a higher dose is required for effects on memory in aged animals. In contrast, $7 \alpha$ hydroxyPREG at the same dose clearly enhanced spatial memory retention after the delay, and this was not attributable to nonspecific effects on swim speeds, which did not change with treatment. Future studies should examine lower doses of $7 \alpha$ hydroxyPREG as well as $7 \alpha$-hydroxyDHEA by intrahippocampal infusion to confirm the primary site of action of the $7 \alpha$ hydroxylated metabolites. Although hippocampal levels of $7 \alpha$ hydroxyPREG and PREG in the treated rats remain to be determined, our data nevertheless show that $7 \alpha$-hydroxyPREG is an active metabolite, at least in enhancing spatial memory retention. Because the cognitively impaired aged rats show a $30-40 \%$ decline in CYP7B bioactivity, some of the PREG administered will still get converted to the $7 \alpha$-hydroxylated metabolite, which may explain the trend for PREG to show some improvement in memory and why the effects of $7 \alpha$-hydroxyPREG in the RAWM was not significantly better than PREG-treated aged rats. One key study would be to treat $C y p 7 b$ knock-out mice (Rose et al., 2001) with PREG or DHEA; the memory-enhancing effects reported previously in mice (Flood et al., 1988, 1995) should be absent in the $C y p 7 b$ knock-out mice if these steroids require activation by $7 \alpha$-hydroxylation.

Consistent with the $7 \alpha$-hydroxy steroids being active, peripheral injection of both $7 \alpha$-hydroxyPREG and $7 \alpha$-hydroxyDHEA have been reported to increase immune responses in mice (Morfin and Courchay, 1994). In addition, $7 \alpha$-hydroxyDHEA can be further converted to 7 -oxo-DHEA by $11 \beta$-HSD1 (Robinzon et al., 2003), itself widespread in the CNS (Moisan et al., 1990), and 7-oxo-DHEA reverses scopolamine-induced memory impairments in young mice (Shi et al., 2000). Indeed, if $7 \alpha$-hydroxylated metabolites are more active than the parent steroid, then this may in part explain why oral DHEA replacement in the elderly has not successfully improved memory (Wolf et al., 1997; Huppert and Van Niekerk, 2001), whereas DHEA administration is effective at improving memory recollection and mood in healthy young subjects (Alhaj et al., 2006), presumably because they maintain greater hippocampal CYP7B activity. It may be that the $7 \alpha$ hydroxylated metabolite rather than the parent steroid would be more effective therapy in the elderly.

The mechanism of action of $7 \alpha$-hydroxyPREG on memory is not clear. PREG can act via nongenomic mechanisms by binding to the $\mathrm{GABA}_{\mathrm{A}}$ and NMDA receptors to enhance neuronal excitability (Paul and Purdy, 1992; Sliwinski et al., 2004). Whether $7 \alpha$-hydroxyPREG also interacts with these membrane receptors and with greater potency has yet to be determined. Antiglucocorticoid effects of $7 \alpha$-hydroxyDHEA have been shown, for example in counteracting dexamethasone-induced thymic and $\mathrm{T}$ cell involution (May et al., 1990). $7 \alpha$-HydroxyDHEA may also be a substrate for $11 \beta$-HSD1 in hepatocytes (Robinzon et al., 2003), suggesting the possibility that it may interfere with $11 \beta$-HSD1 regenerating active glucocorticoids from inert 11-keto forms (Muller et al., 2004). Indeed, $11 \beta$-HSD1 null mice lack local intracellular glucocorticoid regeneration and are protected from the decline in cognitive function seen in wild-type mice (Yau et al., 2001). Whether $7 \alpha$-hydroxyPREG has similar effects to $7 \alpha$ hydroxyDHEA in its neuroprotective (Pringle et al., 2003) and anti-glucocorticoid (May et al., 1990) actions merits additional investigation. If $7 \alpha$-hydroxyPREG had anti-glucocorticoid ef- fects, this could be partly responsible for the enhanced memory retention in the aged impaired rats because elevated glucocorticoid levels correlates with impaired learning in the water maze (Issa et al., 1990; Yau et al., 1995). Although plasma corticosterone levels were not significantly altered by $7 \alpha$-hydroxyPREG or PREG treatment, this does not rule out changes in hippocampal tissue corticosterone levels, which can be very different from circulating levels because of the presence $11 \beta$-HSD1 (Yau et al., 2001). Future work to measure the hippocampal levels of corticosterone and $7 \alpha$-hydroxyPREG as well as other neurosteroids in the cognitively tested aged rats (and young controls) may help elucidate the molecular basis for the enhanced memory in the age-impaired rat after $7 \alpha$-hydroxyPREG treatment. The identification and simultaneous quantification of PREG and DHEA and their $7 \alpha$-hydroxylated metabolites in individual rat hippocampal samples (to allow levels to be correlated with spatial memory) is technically very challenging. Using the LC-MS-MS (a triple quadrupole mass spectrometer with associated HPLC) and after converting the steroids to oxime derivatives to improve the limit of detection, we were able to identify and quantify PREG $(\sim 3$ $\mathrm{ng} / \mathrm{g}$ tissue) and DHEA ( $\sim 1 \mathrm{ng} / \mathrm{g}$ tissue) concentrations but not $7 \alpha$-hydroxyPREG within the same individual control whole rat brain (N. Homer, J. Yau, J. Seckl, and R. Andrew, unpublished preliminary data). A more sensitive method to detect the $7 \alpha$ hydroxyPREG levels will require the development of a radioimmunoassay. Intracerebroventricular administration of PREG-S to rats has been reported previously to enhance acetylcholine release in basolateral amygdala, cortex, and hippocampus (Mayo et al., 2003). If this is attributable in part to the conversion to the $7 \alpha$-hydroxylated metabolite rather than PREG per se, then this could be one possible explanation to the memory-enhancing effects of $7 \alpha$-hydroxyPREG in aged impaired rats. Whatever the mechanism, we have shown that $7 \alpha$-hydroxyPREG is an active metabolite that can enhance memory retention in aged impaired rats that may have reduced CYP7B activity. Direct administration of the $7 \alpha$-hydroxylated steroid product of CYP7B may be a novel therapeutic approach to improve cognitive function with aging in humans.

\section{References}

Akwa Y, Morfin RF, Robel P, Baulieu EE (1992) Neurosteroid metabolism. 7Alpha-hydroxylation of dehydroepiandrosterone and pregnenolone by rat brain microsomes. Biochem J 288:959-964.

Alhaj HA, Massey AE, McAllister-Williams RH (2006) Effects of DHEA administration on episodic memory, cortisol and mood in healthy young men: a double-blind, placebo-controlled study. Psychopharmacology (Berl), in press.

Bean R, Seckl JR, Lathe R, Martin C (2001) Ontogeny of the neurosteroid enzyme Cyp7b in the mouse. Mol Cell Endocrinol 174:137-144.

Dellu F, Mayo W, Vallee M, Le Moal M, Simon H (1997) Facilitation of cognitive performance in aged rats by past experience depends on the type of information processing involved: a combined cross-sectional and longitudinal study. Neurobiol Learn Mem 67:121-128.

Diamond DM, Park CR, Heman KL, Rose GM (1999) Exposing rats to a predator impairs spatial working memory in the radial arm water maze. Hippocampus 9:542-552.

Doostzadeh J, Morfin R (1996) Studies of the enzyme complex responsible for pregnenolone and dehydroepiandrosterone 7a-hydroxylation in mouse tissues. Steroids 61:613-620.

Ebner MJ, Corol DI, Havlikova H, Honour JW, Fry JP (2006) Identification of neuroactive steroids and their precursors and metabolites in adult male rat brain. Endocrinology 147:179-190.

Flood JF, Roberts E (1988) Dehydroepiandrosterone sulfate improves memory in aging mice. Brain Res 448:178-181.

Flood JF, Smith GE, Roberts E (1988) Dehydroepiandrosterone and its sulfate enhance memory retention in mice. Brain Res 447:269-278. 
Flood JF, Morley JE, Roberts E (1992) Memory-enhancing effects in male mice of pregnenolone and steroids metabolically derived from it. Proc Natl Acad Sci USA 89:1567-1571.

Flood JF, Morley JE, Roberts E (1995) Pregnenolone sulfate enhances posttraining memory processes when injected in very low doses into limbic system structures: the amygdala is by far the most sensitive. Proc Natl Acad Sci USA 92:10806-10810.

Gallagher M, Burwell R, Burchinal M (1993) Severity of spatial learning impairment in aging: development of a learning index for performance in the Morris water maze. Behav Neurosci 107:618-626.

Hampl R, Lapcik O, Hill M, Klak J, Kasal A, Novacek A, Sterzl I, Sterzl J, Starka L (2000) 7-Hydroxydehydroepiandrosterone-a natural antiglucocorticoid and a candidate for steroid replacement therapy? Physiol Res 49:S107-S112.

Huppert FA, Van Niekerk JK (2001) Dehydroepiandrosterone (DHEA) supplementation for cognitive function. Cochrane Database Syst Rev:CD000304.

Issa AM, Rowe W, Gauthier S, Meaney MJ (1990) Hypothalamic-pituitaryadrenal activity in aged, cognitively impaired and cognitively unimpaired rats. J Neurosci 10:3247-3254.

Ladurelle N, Eychenne B, Denton D, Blair-West J, Schumacher M, Robel P, Baulieu E (2000) Prolonged intracerebroventricular infusion of neurosteroids affects cognitive performances in the mouse. Brain Res 858:371-379.

Lafaye P, Chmielewski V, Nato F, Mazie JC, Morfin R (1999) The 7alphahydroxysteroids produced in human tonsils enhance the immune response to tetanus toxoid and Bordetella pertussis antigens. Biochim Biophys Acta 1472:222-231.

Le Goascogne C, Sananes N, Gouezou M, Takemori S, Kominami S, Baulieu EE, Robel P (1991) Immunoreactive cytochrome P-450(17 alpha) in rat and guinea-pig gonads, adrenal glands and brain. J Reprod Fertil 93:609-622.

Loria RM, Padgett DA (1998) Control of the immune response by DHEA and its metabolites. Rinsho Byori 46:505-517.

May M, Holmes E, Rogers W, Poth M (1990) Protection from glucocorticoid induced thymic involution by dehydroepiandrosterone. Life Sci 46:1627-1631.

Mayo W, George O, Darbra S, Bouyer JJ, Vallee M, Darnaudery M, Pallares M, Lemaire-Mayo V, Le Moal M, Piazza PV, Abrous N (2003) Individual differences in cognitive aging: implication of pregnenolone sulfate. Prog Neurobiol 71:43-48.

Mellon SH, Deschepper CF (1993) Neurosteroid biosynthesis: genes for adrenal steroidogenic enzymes are expressed in the brain. Brain Res 629:283-292.

Moisan M-P, Seckl JR, Edwards CRW (1990) 11 $\beta$-hydroxysteroid dehydrogenase bioactivity and messenger RNA expression in rat forebrain: localization in hypothalamus, hippocampus and cortex. Endocrinology 127:1450-1455.

Morfin R, Courchay G (1994) Pregnenolone and dehydroepiandrosterone as precursors of native 7-hydroxylated metabolites which increase the immune response in mice. J Steroid Biochem Mol Biol 50:91-100.

Morfin R, Starka L (2001) Neurosteroid 7-hydroxylation products in the brain. Int Rev Neurobiol 46:79-95.

Muller C, Cluzeaud F, Pinon GM, Rafestin-Oblin ME, Morfin R (2004) Dehydroepiandrosterone and its 7-hydroxylated metabolites do not interfere with the transactivation and cellular trafficking of the glucocorticoid receptor. J Steroid Biochem Mol Biol 92:469-476.

Orentreich N, Brind JL, Vogelman JH, Andres R, Baldwin H (1992) Longterm longitudinal measurements of plasma dehydroepiandrosterone sulphate in normal men. J Clin Endocrinol Metab 75:1002-1004.

Paul SM, Purdy RH (1992) Neuroactive steroids. FASEB J 6:2311-2322.

Pringle AK, Schmidt W, Deans JK, Wulfert E, Reymann KG, Sundstrom LE (2003) 7-Hydroxylated epiandrosterone (7-OH-EPIA) reduces ischaemia- induced neuronal damage both in vivo and in vitro. Eur J Neurosci $18: 117-124$.

Robel P, Baulieu EE (1995) Neurosteroids: biosynthesis and function. Crit Rev Neurobiol 9:383-394.

Robinzon B, Michael KK, Ripp SL, Winters SJ, Prough RA (2003) Glucocorticoids inhibit interconversion of 7-hydroxy and 7-oxo metabolites of dehydroepiandrosterone: a role for 11beta-hydroxysteroid dehydrogenases? Arch Biochem Biophys 412:251-258.

Rose K, Allan A, Gauldie S, Stapleton G, Dobbie L, Dott K, Martin C, Wang L, Hedlund E, Seckl JR, Gustafsson JA, Lathe R (2001) Neurosteroid hydroxylase CYP7B: vivid reporter activity in dentate gyrus of gene-targeted mice and abolition of a widespread pathway of steroid and oxysterol hydroxylation. J Biol Chem 276:23937-23944.

Rose KA, Stapleton G, Dott K, Kieny MP, Best R, Schwarz M, Russell DW, Björkhem I, Seckl J, Lathe R (1997) Cyp7b, a novel brain cytochrome P450, catalyzes the synthesis of neurosteroids 7a-hydroxy dehydroepiandrosterone and 7a-hydroxy pregnenolone. Proc Natl Acad Sci USA 94:4925-4930.

Seckl JR (1997) 11Beta-hydroxysteroid dehydrogenase in the brain: a novel regulator of glucocorticoid action? Front Neuroendocrinol 18:49-99.

Shi J, Schulze S, Lardy HA (2000) The effect of 7-oxo-DHEA acetate on memory in young and old C57BL/6 mice. Steroids 65:124-129.

Sliwinski A, Monnet FP, Schumacher M, Morin-Surun MP (2004) Pregnenolone sulfate enhances long-term potentiation in CA1 in rat hippocampus slices through the modulation of $N$-methyl-D-aspartate receptors. J Neurosci Res 78:691-701.

Stapleton G, Steel M, Richardson M, Mason JO, Rose KA, Morris RGM, Lathe R (1995) A novel cytochrome P450 expressed primarily in brain. J Biol Chem 270:29739-29745.

Vallee M, Mayo W, Darnaudery M, Corpechot C, Young J, Koehl M, Le Moal M, Baulieu EE, Robel P, Simon H (1997) Neurosteroids: deficient cognitive performance in aged rats depends on low pregnenolone sulfate levels in the hippocampus. Proc Natl Acad Sci USA 94:14865-14870.

Vallee M, Mayo W, Le Moal M (2001) Role of pregnenolone, dehydroepiandrosterone and their sulfate esters on learning and memory in cognitive aging. Brain Res Brain Res Rev 37:301-312.

Vallee M, George O, Vitiello S, Le Moal M, Mayo W (2004) New insights into the role of neuroactive steroids in cognitive aging. Exp Gerontol 39:1695-1704.

van Groen T, Kadish I, Wyss JM (2002) Old rats remember old tricks; memories of the water maze persist for 12 months. Behav Brain Res 136:247-255.

Weill-Engerer S, David JP, Sazdovitch V, Liere P, Schumacher M, Delacourte A, Baulieu EE, Akwa Y (2003) In vitro metabolism of dehydroepiandrosterone (DHEA) to 7alpha-hydroxy-DHEA and Delta5-androstene3beta,17beta-diol in specific regions of the aging brain from Alzheimer's and non-demented patients. Brain Res 969:117-125.

Wolf OT, Neumann O, Hellhammer DH, Geiben AC, Strasburger CJ, Dressendorfer RA, Pirke KM, Kirschbaum C (1997) Effects of a twoweek physiological dehydroepiandrosterone substitution on cognitive performance and well-being in healthy elderly women and men. J Clin Endocrinol Metab 82:2363-2367.

Yau JL, Olsson T, Morris RGM, Meaney MJ, Seckl JR (1995) Glucocorticoids, hippocampal corticosteroid receptor gene expression and antidepressant treatment: relationship with spatial learning in young and aged rats. Neuroscience 66:571-581.

Yau JL, Noble J, Kenyon CJ, Hibberd C, Kotelevtsev Y, Mullins JJ, Seckl JR (2001) Lack of tissue glucocorticoid reactivation in 11 beta -hydroxysteroid dehydrogenase type 1 knockout mice ameliorates agerelated learning impairments. Proc Natl Acad Sci USA 98:4716-4721.

Yau JL, Rasmuson S, Andrew R, Graham M, Noble J, Olsson T, Fuchs E, Lathe R, Seckl JR (2003) Dehydroepiandrosterone 7-hydroxylase CYP7B: predominant expression in primate hippocampus and reduced expression in Alzheimer's disease. Neuroscience 121:307-314. 